\title{
Assessment of West Liaohe River Basin's Ecological Vulnerability and Temporal-Spatial Distribution based on Landscape Pattern
}

Feng Zhang, Jquan Zhang, Yanan Chen, Qiyun Ma, Enliang Guo, Yongfang Wang School of Environment, Northeast Normal University, Institute of Natural Disaster Research, Northeast Normal University, Changchun 130024, China

\section{基于景观格局的西辽河流域生态脆弱性评价及时空分 布特征}

\author{
张峰, 张继权 ${ }^{\dagger}$, 陈亚南, 马齐云, 郭恩亮, 王永芳 \\ 东北师范大学环境学院, 东北师范大学自然灾害研究所, 长春 130024 , 中国
}

\begin{abstract}
West Liaohe River Basin, which is known as a typical ecological vulnerable district of Northeast China, is taken as a case study in this paper. By collecting 3 period Landsat TM image of 1992,2002 and 2012, the landscape pattern figure is interpreted. Landscape sensitivity index and landscape adaptability index were selected to calculate ecological vulnerabillity index. We analysed landscape pattern, vulnerable degrees spatio-temporal distribution and vulnerable degrees spatio-temporal changes features. The main conclusions were as follows: (1) Landscape was dominated by farmland and woodland, and by the rapid economic development of human society, the building land in the study area increased rapidly, while there was a decreasing trend in the waters, woodland and desertified land; (2) The West Liaohe River basin vulnerability overall has a downward trend. The high vulnerability and high vulnerability areas transferred from Southwest mountainous area of Chifeng City to the area around Tongliao city. In recent years these areas gather to naiman banner and Wengniute Banner, Inner Mongolia;(3) vulnerability changes area is distributed over the rapid economic
\end{abstract}

development of Tongliao City around in the fist 10 years, and the rapid rise is very fragile. And there is a rapid decline in nearly 10 years. The results are significant to guide the ecological management in this area.

Keywords: landscape pattern; vulnerability assessment; West Liaohe River Basin; temporal-spatial distribution

\section{摘要}

以东北典型生态脆弱区西辽河流域为研究区, 收集 1992,2002 和 2012 年 3 期 Landsat TM 影像进行景 观类型解译, 根据景观敏感性和景观适应性 2 个维 度选取景观指数并计算生态脆弱性指数, 分析景观 格局、脆弱度时空分布和脆弱度时空变化特征。主 要结论如下: (1) 景观类型以耕地和林地为主, 耕 地和建筑用地面积快速增加, 林地、水域呈减少趋 势, 沙化土地有改善态势; (2) 西辽河流域脆弱度 总体呈下降趋势, 较高脆弱区和高脆弱区范围由赤 峰西南部山区向通辽市辖区周围转移, 近年来龟缩 于奈曼旗和翁牛特旗地区; (3) 脆弱度的变化主要 集中于通辽市辖区周围, 前 10 年主要呈脆弱等级

“作者简介: 张峰, (1989-) , 男, 汉族, 东北师范大学博士研究生, 主要从事灾害与生态脆弱性评价研究。 通讯作者: 张继权 (1965-), 男, 吉林九台人, 教授, 博士(后), 博士生导师, 主要从事区域灾害与生态环境风险评价、 预警与应急管理研究。E-mail: zhangjq022@nenu.edu.cn 
Risk Analysis and Crisis Response in Big Data Era (RAC-16)

快速上升趋势; 近 10 年来呈快速下降趋势。研究 结果对指导该区生态管理具有一定的现实意义。

关键词: 景观格局; 脆弱性评价; 西辽河流域; 时 空分布

\section{1. 引言}

随着生态环境的不断恶化, 导致生态系统的格局、 过程和服务功能也趋于退化, 进而严重威胁着生态 系统和社会经济系统的可持续发展 [1]。自 20 世纪 80 年代以来, 生态脆弱性研究成为适应和减缓环 境恶化问题的关键内容, 成为生态学领域研究的热 点。生态脆弱性研究不仅能为脆弱生态地区恢复重 建工作提供科学依据, 同时也是制定区域可持续发 展规划的重要前提[2]。然而, 生态脆弱性的概念至 今仍没有一个定论[3], 其争论的焦点在于暴露性是 否是构成脆弱性的要素之一[4]。现今学界普遍认为 脆弱性与暴露、干扰、适应性、敏感性、恢复力、 稳定性等因素紧密相关, 而且是一个相对的概念, 是可以度量的。生态脆弱性的评价研究是生态脆弱 性研究的基础, 根据对生态脆弱性概念的不同认 识, 其评价方法也有所不同 [5], 经过近年来的发展, 生态脆弱性评价已形成了多种较为成熟的评价体 系[6], 所采用的评价方法主要有模糊综合评判法、 EVI（Ecological Vulnerability Index）法、层次分析 法、主成分分析法、关联评价法、综合评价法以及 基于遥感、GIS 的图层叠加、景观格局指数法等 [7-11]。其中，基于景观格局的评价方法因其能够 综合反映自然与人为因素在生态过程中相互作用 的结果, 能够建立起更加全面、科学的指标体系, 并且操作方便, 因而得到迅速发展[12]。

西辽河流域大部分地区处于干旱、半干旱气候 区, 年均降水量极其稀少, 降水径流关系极不稳定, 难以维系稳定的地表径流, 而植物在降水较少是只 能依靠地下水来维持生存, 西辽河流域社会经济在 近年来得到了快速发展, 对包括水资源在内的各类 自然资源进行了无序开发, 造成地下水漏斗、地表 径流断流等严重生态问题, 对景观生态造成了严重 破坏[13], 因此, 亟需在该区域进行生态脆弱性评 价研究, 研究成果对指导西辽河流域的生态恢复和 管理具有一定的指导作用。

本文对西辽河流域 1992 年、2002 年和 2012 年的 Landsat TM 影像进行遥感解译, 得到研究区 这 3 个时期的景观分类图, 通过建立相应的景观格 局指数构造生态脆弱度计算模型, 最终利用
Fragstats、Excel、ArcGIS 等软件对生态脆弱度进 行计算和时空演变特征的分析。

\section{2. 数据与方法}

\section{1 数据来源与处理}

通过地理空间数据云网站收集 1992 年、 2002 年和 2012 年 3 个时期研究区的 Landsat TM 影像, 每期 影像共 13 幅, 行列编号分别为 119/29、119/30、 120/29、120/30、121/29、121/30、121/31、122/29、 $122 / 30 、 122 / 31 、 123 / 29 、 123 / 30 、 123 / 31$, 为避免 干扰, 影像拍摄日期选取非植物生长季的秋季 (10 月、11 月), 并且无云或少云的天气。以中国县市 行政区划图 (1:400 万)、2000 年西辽河流域土地 利用现状图等为辅助数据, 以《土地利用现状分类 标准(GBT_21010-2007)》中的一级土地利用类型分 类标准为基础, 将景观类型划分为耕地、林地、草 地、水域、建设用地和未利用地 6 种景观类型。通 过 ENVI 5.0 软件进行辐射校正、几何校正、影像 融合、图像镶嵌等前处理过程, 结合野外调查和相 关文献资料, 确定解译标志, 然后进行室内解译, 最终得到 3 期西辽河流域景观类型分布图。综合考 虑尺度效应和研究区面积大小, 结合前人研究经验 [14], 对本区域进行单元网格的划分。本文将研究 区以 $5 \mathrm{~km} \times 5 \mathrm{~km}$ 的网格进行划分, 最终得到 5770 个格网。将这些网格作为生态脆弱度小区, 并计算 每个小区的生态脆弱度大小。

\section{2 研究区概况}

西辽河流域位于辽河上游, 介于 $41^{\circ} 05^{\prime} \mathrm{N} \sim 45^{\circ} 13^{\prime} \mathrm{N}$ 、 $116^{\circ} 107^{\prime} \mathrm{E} \sim 123^{\circ} 35^{\prime} \mathrm{E}$, 土地面积约为 13.6 万 $\mathrm{km}^{2}$, 占辽河流域的 $43 \%$ 。流域内涉及的行政区划包括 通辽市、赤峰市、兴安盟、锡林郭勒盟、四平市、 白城市、松原市、承德市、朝阳市与沈阳市 10 个 盟市, 27 个旗/县/区(图 1)。西辽河流域属于温带 大陆性半干旱气候类型, 平均温度 $6.4^{\circ} \mathrm{C}, \geq 10^{\circ} \mathrm{C}$ 积 温为 $3151.2^{\circ} \mathrm{C}$, 无霜期 151 天, 多年平均降水量 $364.6 \mathrm{~mm}$, 主要集中在 6 9 月份, 占全年降水的 $80 \%$; 多年平均蒸发量 $1972.8 \mathrm{~mm}$, 是降水量的 5 倍多, 年平均风速 $3.5 \mathrm{~m} / \mathrm{s}$, 春季平均风速 $4.4 \mathrm{~m} / \mathrm{s}$, 干旱和大风在季节上的同步, 使土壤更容易遭受风 蚀。西辽河是松辽流域最干旱少雨地区。地带性植 被生态主要为半干旱草原, 在 $300 \mathrm{~mm}$ 降水区域存 在半固定沙丘, 是东北地区生态最脆弱地区。由于 大规模土地灌溉, 河道断流、地下水位下降, 导致 部分地区草原和荒漠植被均不同程度地退化。同 时, 水土流失比较严重, 河流泥沙含量大。 
Risk Analysis and Crisis Response in Big Data Era (RAC-16)

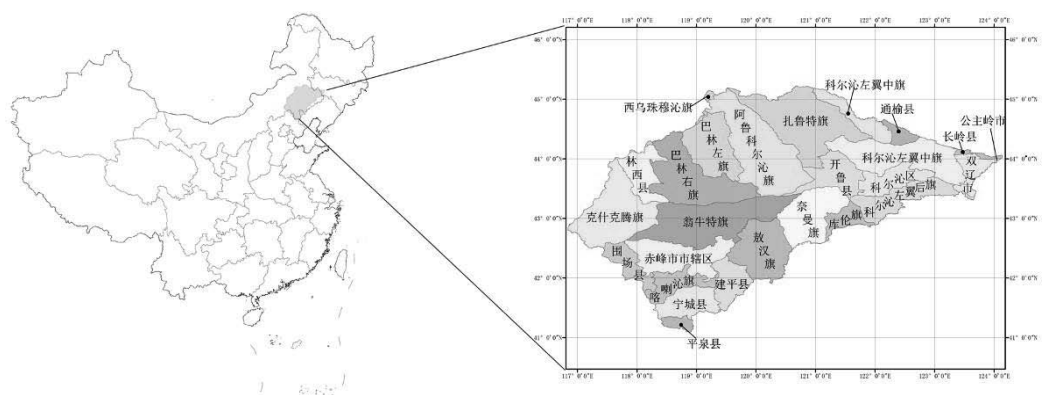

图 1 研究区区位图

\section{3 基于景观格局的生态脆弱性指数构建}

根据景观格局的概念, 景观格局可以表现由自 然或人为干扰下造成一系列大小、形状各异、排列 不同的景观要素这一结果, 也在某种程度上反映了 各种生态过程的变化 [15]。通过景观指数来使景观 格局量化, 可以在景观结构和过程之间建立直观的 联系, 从而更好地解释景观功能[16]。基于景观指 数的生态脆弱性水平取决于人类活动干扰对景观 格局造成的异质性以及系统本身的反应能力。近年 来, 学界通过构建景观敏感度指数 ( $L S I)$ 和景观 适应度指数 ( $L A I)$ 来构建景观脆弱度指数 ( $L V I)$ $[17,18]$ 。本文通过景观干扰度指数 $\left(U_{i}\right)$ 和景观类 型易损度 $\left(V_{i}\right)$ 来表征景观敏感度, 选取斑块多度 密度指数 $(P R D)$ 、香农多样性指数 (SHDI) 和香 农均匀性指数 (SHEI) 来构建景观适应度指数。其 中, 景观干扰度指数的计算选取了景观破碎度 $\left(F N_{i}\right)$ 、景观分维数倒数 $\left(F D_{i}\right)$ 和景观优势度 $\left(D O_{i}\right)$, 经过加权求得, 其权重根据相关文献 [19], 通常取为 $0.5 、 0.3 、 0.2$ 。相关计算公式如下:

$L V I=L S I \times(1-L A I)$

(1)

$L S I=\sum_{i=1}^{n} U_{i} \times V_{i}$

$U_{i}=a F N_{i}+b F D_{i}+c D O_{i}$

(3)

$L A I=P A D \times S H D I \times S H E I$

式中, 景观类型易损度 $\left(V_{i}\right)$ 借鉴他人对土地利用 易损度的研究成果 [20], 结合专家经验对各个景观 类型进行赋值。其中未利用地 $=7$, 林地、草地 $=5$, 耕地 $=3$, 建设用地、水域 $=1$ 。以上各个景观指数的 计算通过 Fragstats 和 Excel 软件进行计算。

3 结果分析

3.1 景观类型变化特征分析

利用 RS 和 GIS 技术, 对西辽河流域 1992 年、 2002 年和 2012 年 6 种景观类型进行遥感解译, 得到 3 个时期的景观类型分布图 (图 2), 通过 ArcGIS 软 件, 对研究区景观面积进行了分类汇总, 如表 1 所 示。

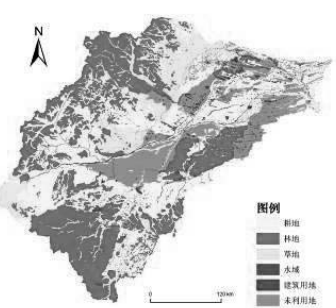

1992 年

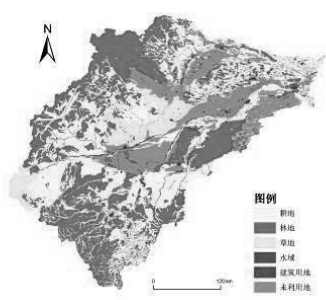

2002 年

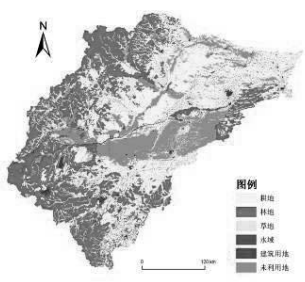

2012 年

图 2 1992-2012 年西辽河流域景观类型变化图 
Risk Analysis and Crisis Response in Big Data Era (RAC-16)

表 1 景观类型面积及比例

\begin{tabular}{|c|c|c|c|c|c|c|}
\hline \multirow[b]{2}{*}{ 景观类型 } & \multicolumn{2}{|c|}{1992 年 } & \multicolumn{2}{|c|}{2002} & \multicolumn{2}{|c|}{2012} \\
\hline & $\begin{array}{l}\text { 面积 } \\
\left(\mathrm{hm}^{2}\right)\end{array}$ & $\begin{array}{c}\text { 占总面积 } \\
\text { 比例 } \\
(\%)\end{array}$ & $\begin{array}{l}\text { 面积 } \\
\left(\mathrm{hm}^{2}\right)\end{array}$ & $\begin{array}{c}\text { 占总面积 } \\
\text { 比例 } \\
(\%)\end{array}$ & $\begin{array}{l}\text { 面积 } \\
\left(\mathrm{hm}^{2}\right) \\
\end{array}$ & $\begin{array}{c}\text { 占总面积 } \\
\text { 比例 } \\
(\%)\end{array}$ \\
\hline 耕地 & 4898295.91 & 37.01 & 4656182.45 & 31.61 & 6032983.60 & 45.59 \\
\hline 林地 & 4650599.97 & 35.14 & 4748431.21 & 35.88 & 4482091.78 & 33.87 \\
\hline 草地 & 1402615.09 & 10.60 & 1277796.37 & 9.66 & 195081.04 & 1.47 \\
\hline 水域 & 339457.33 & 2.57 & 244062.63 & 1.84 & 201251.06 & 1.52 \\
\hline 建设用地 & 89623.37 & 0.68 & 124054.49 & 0.94 & 344534.66 & 2.60 \\
\hline 未利用地 & 1852877.12 & 14.00 & 2182941.64 & 16.50 & 1977526.65 & 14.94 \\
\hline 合计 & 13233468.79 & 100.00 & 13233468.79 & 100.00 & 13233468.79 & 100.00 \\
\hline
\end{tabular}

景观格局由于受自然和人为的干扰而呈现出 异质性, 同时, 景观格局的变化与自然环境的改变 及人类社会经济活动的影响是分不开的。从图 2 和 表 1 中可以看出, 在西辽河流域, 耕地和林地是主 要的两种景观类型, 在各个年份中, 两种景观类型 合计均能达到 $65 \%$ 以上。其中林地主要分布在研究 区的北部、西部和西南部地区, 耕地分布在中部和 东部的广大平原地区。草地、水域和建设用地分布 较为分散, 破碎度较大。未利用地在该区主要为沙 地, 主要分布在著名的科尔沁沙地。在近 20 年的 发展中, 随着人口的增长和社会经济的不断发展, 耕地面积和建设用地的面积有了明显的增加, 其中 耕地面积呈现先减少后增加的趋势, 而建设用地面 积则不断增加。水域面积呈减少趋势, 这与该区域 生态环境的恶化和工业用水和灌溉用水的不断增

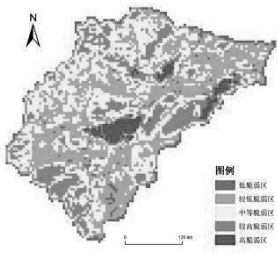

1992 年

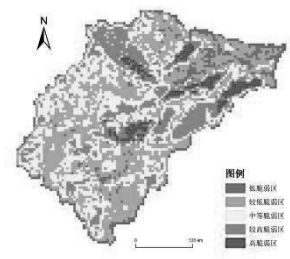

2002 年
加, 造成的水资源严重短缺具有密切关系。未利用 地即沙漠化土地在这一时期呈现先增加后减少的 趋势, 可见自 2000 年以来, 我国大力推广实施的“退 耕还林还草”政策具有一定的成效。

\section{2 基于景观格局的生态脆弱度时空分布}

为了使生态脆弱度可以直观地显示其在时间和空 间上的差异性，先采用 ArcGIS 软件的等间距法将 生态脆弱度划分为 5 个等级, $0 \sim 3.2$ 为低脆弱区, 3.2 6.4 为较低脆弱区、6.4 9.6 为中等脆弱区, 9.6 12.8 为较高脆弱区, $>12.8$ 为高脆弱区。在 ArcGIS 软件中生成了 3 期基于景观格局的西辽河 生态脆弱度空间分布图 (图 3), 并对这 5 个分区 在不同时期内的面积进行了统计 (表 2)。

图 3 1992-2012 年西辽河流域生态脆弱度空间分布

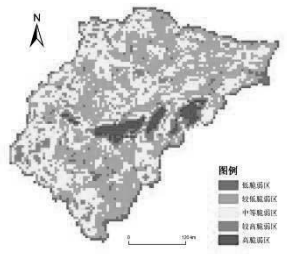

2012 年

表 2 生态脆弱分区各年比例及其变化情况

\begin{tabular}{cccccc}
\hline 时期 & 低脆弱区 & 较低脆弱区 & 中等脆弱区 & 较高脆弱区 & 高脆弱区 \\
\hline 1992 & 5.03 & 37.05 & 37.28 & 17.30 & 3.34 \\
2002 & 8.28 & 37.94 & 32.65 & 17.56 & 3.57 \\
2012 & 6.50 & 46.15 & 36.62 & 7.45 & 3.28 \\
\hline
\end{tabular}

如图 3 和表 2 所示, 西辽河流域生态脆弱度总 体呈下降趋势, 其中 2012 年区域内较高脆弱区和 高脆弱区面积均有明显减少, 较低脆弱区面积明显
增加, 其中较高脆弱区面积比例由 1992 年的 $17.30 \%$ 减少到 2012 年的 $7.45 \%$ 。面积的显著变化 带来的是空间格局的改变, 较高脆弱区和高脆弱区 
Risk Analysis and Crisis Response in Big Data Era (RAC-16)

的分布范围由分散逐步变为集中, 由原来分布在北 部的阿鲁科尔沉旗、开鲁县、科左中旗和扎鲁特旗 地区逐渐龟缩于奈曼旗和翁牛特旗的科尔沉沙地 地区。

从各个分级区的变化来看, 1992 年到 2002 年 之间各等级面积总体变化不大, 但空间格局具有较 为显著的变化。主要体现在较高脆弱区和高脆弱区 由原来在赤峰市西南部山区的分布, 向通辽市辖区 内的开鲁县、科左后旗及扎鲁特旗等地转移。这些 地区由于改革开放以来人口的急剧增长, 经济的快 速起飞, 对生态环境造成了一定的压力。而到了 2002 年-2012 年这一时期, 随着人们意识到生态脆 弱性对环境和人类可持续发展的影响, 开始实行 “退耕还林还草”、建设社会主义新农村、新牧区等 政策, 并且在一些较为发达地区取得了显著的成 效, 因此, 高脆弱区和较高脆弱区的面积有了显著 的减少, 取而代之的是较低脆弱区的范围有了显著 增加。而低脆弱区的面积没有明显变化, 这说明相 关政策的落实和产生效果需要时间性和过程性。

\section{3 生态脆弱度的变化特征}

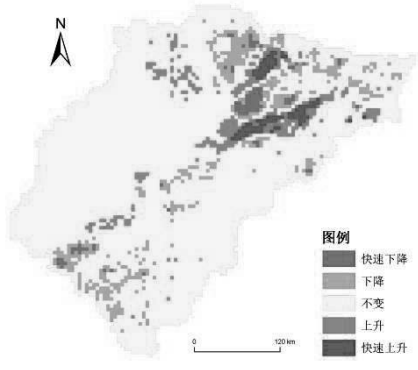

1992-2002

图 4 西辽河流域景观脆弱度变化分布
根据相邻两个时期研究区每个网格脆弱度等级的 变化程度, 将其划分为 5 个等级, 分别为: 快速下 降 (脆弱度下降 1 个等级以上)、下降 (脆弱度下 降 1 个等级)、不变、上升 (脆弱度上升 1 个等级)、 快速上升 (脆弱度上升 1 个等级)。将计算好的网 格等级变化同样通过 ArcGIS 软件进行空间制图 (图 4)。由图可知, 1992-2002 年期间, 研究区内 大部分区域等级均未发生变化, 脆弱度上升及快速 上升的区域主要集中在通辽市市辖区及其周边的 开鲁县、扎鲁特旗、科左中旗等地, 并且脆弱度快 速下降的地区也恰恰在快速上升区域的周围。这一 现象首先证实了上一小节对脆弱度分布特征的分 析, 其次, 也正好说明了这一区域在 20 世纪末期 是人类活动迅速发展的时期，人类在发展自身的同 时有可能给生态系统造成或正向或负向的干扰, 并 且这种生态系统对这种干扰是十分敏感的。 2002-2012 年期间, 脆弱度发生变化的区域虽然仍 然零散, 但呈明显增多趋势, 并且脆弱度下降的区 域较多, 生态环境趋于改善, 尤其是通辽市辖区周 围, 生态脆弱度显著下降。

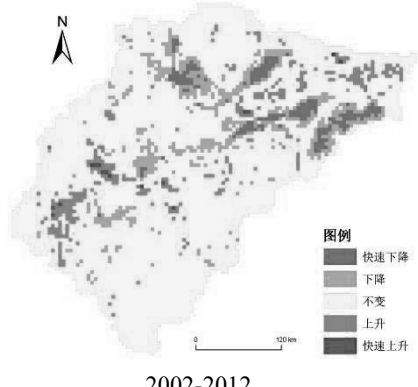

2002-2012

\section{4 结论}

本文以 1992，2002 和 2012 年 3 期 Landsat TM 影 像为数据源, 以西辽河流域为研究区, 通过影像前 处理和室内解译, 获得研究区景观格局图, 选取景 观敏感性和景观适应性指数构建了基于景观格局 的生态脆弱性指数, 利用 Fragstas、 Excel 和 ArcGIS 等软件进行计算和脆弱度的空间化表达, 通过对景 观格局、脆弱度时空分布和脆弱度时空变化特征的 分析得到如下结论:

(1) 在短期景观格局演变过程中, 人类活动
的干扰对景观异质性起主导作用。西辽河流域景观 类型以耕地和林地为主, 受人类社会经济的快速发 展, 研究区内耕地和建筑用地面积快速增加, 林地、 水域呈减少趋势, 沙化土地有改善态势。

（2）西辽河流域脆弱度总体呈下降趋势, 较 高脆弱区和高脆弱区范围由赤峰西南部山区向通 辽市辖区周围转移, 近年来龟缩于奈曼旗和翁牛特 旗地区。

(3) 脆弱度的变化在前 10 年主要集中于经济 快速发展的通辽市辖区周围, 主要呈脆弱等级快速 上升趋势; 近 10 年来通辽市辖区周围呈脆弱度等 级快速下降趋势, 并且全区均零散分布有脆弱度快 
Risk Analysis and Crisis Response in Big Data Era (RAC-16)

速下降和下降的区域。

受研究者收集资料和知识水平所限, 对基于景 观格局的生态脆弱性研究缺少生态学意义的探讨 和社会经济驱动机制的定量分析, 这将是本研究今 后努力的方向。

\section{Acknowledgements}

The study is financially supported by the National Non-Profit Research Program of China (No.201401015)

\section{致谢}

本研究得到了水利部公益性行业科研专项经费项 目 (201401015) 的资助。

\section{参考文献}

[1] Martins V. Nuno, Rui Pires, Cabral Pedro. Modelling of coastal vulnerability in the stretch between the beaches of Porto de Mós and Falésia, Algarve (Portugal). Journal of Coastal Conservation. 16(4):503-510, 2012.

[2] 张笑楠, 王克林, 张伟, 陈洪松, 何寻阳. 桂西北 喀斯特区域生态环境脆弱性. 生态学报. 29(2):749-757, 2009.

[3] Timmerman Peter.Vulnerability resilience and collapse of society.A Review of Models and Possible Climatic Applications. Toronto, Canada:Institute for Environmental Studies, University of Toronto, 1981.

[4] 李鹤, 张平宇, 程叶青.脆弱性的概念及其评价方 法.地理科学进展. 27(02):18-25, 2008.

[5] 徐广才, 康慕谊, 贺丽娜, 李亚飞, 陈雅如. 生 态脆弱性及其研究进展. 生态学报. 29(05): 2578-2588, 2009.

[6] Turner Billie L., Kasperson Roger E., Matson Pamela A., McCarthy James J., Corell Robert W., Christensen Lindsey, Eckley Noelle, Kasperson Jeanne X., Luers Amy, Martello Marybeth L..A framework for vulnerability analysis in sustainability science. Proceedings of the national academy of sciences. 100(14):8074-8079, 2003.
Analysis and Crisis Response, 2(3): 195-20 2012.

[8] Pang Xilei. Dynamic Vulnerability Analysis c Population for Flood Disaster in Urban Are Journal of Risk Analysis and Crisis Respons. 3(4): 166-174, 2013.

[9] Metzger Marc J., Leemans Rik, Schröter Dagma A multidisciplinary multi-scale framework $\mathrm{ft}$ assessing vulnerabilities to global chang International Journal of Applied Ean Observation \& Geoinformation. 7(4): 253-26 2005.

[10]Ding Mingtao, Miao Cheng. GIS-base Assessment of Vulnerability to Landslic Hazards in Lushan Earthquake-stricken Area Journal of Risk Analysis and Crisis Respons. 5(2): 93-106, 2015.

[11]李辉, 张利华, 吴君峰, 张鹏. 基于 GIS的鄱 湖流域生态脆弱性评价. 华中师范大学学报: , 然科学版. 45(1):145-149, 2011.

[12] 邱彭华, 徐颂军, 谢跟踪, 唐本安, 毕华, 余; 师. 基于景观格局和生态敏感性的海南西部土 区生态脆弱性分析. 生态学报, 27(4): 1257 1264, 2007.

[13]王耕, 吴伟.基于 GIS的西辽河流域生态安全? 间分异特征.环境科学. 26(05):28-33, 2005.

[14]高宾, 李小玉, 李志刚, 陈玮, 何兴元, 齐善忠 基于景观格局的锦州湾沿海经济开发区生云 风险分析.生态学报. 31(12):3441-3450, 2011.

[15] 陈利顶,傅伯杰.干扰的类型、特征及其生态 意义.生态学报. 20(04):581-586, 2000.

[16]张金屯, 邱扬,郑风英. 景观格局的数量研究方泣 山地学报. (04):346-352, 2000.

[17]孙才志,闰晓露,钟敬秋.下辽河平原景观格局月 弱性及空间关联格局. 生态学报 34(02):247-257, 2014.

[18]任志远, 张晗. 银川盆地土地利用变化对景又 格局脆弱性的影响. 应用生态学报. 27(01 243-249, 2016.

[19]游巍斌,何东进,巫丽芸, 洪伟, 詹仕华, 覃德华 游惠明.武夷山风景名胜区景观生态安全度日 空分异规律. 生态学报. 31(21): 6317-632 2011. 